\title{
An Investigation of a Knowledge Management Solution for the Improvement of Reference Services
}

\author{
Lynette L. Ralph \\ Linus A. Sims Memorial \\ Library, Southeastern \\ Louisiana University, \\ Hammond, LA, USA
}

Iralph@selu.edu

\author{
Timothy J. Ellis \\ Nova Southeastern University \\ Graduate School of Computer \\ and Information Sciences \\ Fort Lauderdale, Florida, USA
}

\author{
ellist@nova.edu
}

\begin{abstract}
This study investigated the use of the knowledge base of QuestionPoint as a knowledge management tool capable of improving reference services in academic libraries. The research addressed the problem that reference librarians continually provide ineffective service to patrons. Because of the expansive exposure to resources, it is often difficult for any individual librarian to accurately recall the best resource or answer for any specific question. While individual librarians may not recall specific information, when they collaborate with their colleagues and share their collective knowledge there is usually an improvement in the quality of service they provide. It would benefit librarians therefore, if they used a knowledge management tool that could capture and store their communal knowledge for future use. This study explored the librarians' perceptions of the benefits and problems of using the Knowledge Base of QuestionPoint and its impact of on reducing response time and duplication. The study revealed that the reference librarians did not generally use the Knowledge Base, and that there was duplication of effort and no reduction in response time.
\end{abstract}

Keywords: Knowledge management, knowledge sharing, academic libraries, reference service.

\section{Introduction}

In recent years, researchers have recognized the importance of knowledge as an asset to an organization (Gandhi, 2004; Rowley, 1999). Knowledge resides in various places in an organization and represents experiences, education, and other valuable lessons for the management and operation of the organization (Alavi, 2000). Recently, libraries have acknowledged that because they

Material published as part of this publication, either on-line or in print, is copyrighted by the Informing Science Institute. Permission to make digital or paper copy of part or all of these works for personal or classroom use is granted without fee provided that the copies are not made or distributed for profit or commercial advantage AND that copies 1) bear this notice in full and 2) give the full citation on the first page. It is permissible to abstract these works so long as credit is given. To copy in all other cases or to republish or to post on a server or to redistribute to lists requires specific permission and payment of a fee. Contact Publisher@InformingScience.org to request redistribution permission. have been traditionally responsible for the organization of knowledge, they must not only engage in organization, but must also actively spearhead initiatives for the management of that knowledge (Prokopiadou, Papatheodorou, \& Moschopoulos, 2004; Stern, 2003.

A reference librarian in an academic library answers hundreds of questions each year. To answer these questions, a reference librarian refers to a significant 
number of resources in a variety of formats, such as books, journals, the library catalog, electronic databases, and the Internet. This process of identifying information for patrons has allowed reference librarians to acquire a vast amount of tacit, as well as explicit, knowledge. Because of the exposure to this vast amount of information and resources, it is impossible for any individual reference librarian to have complete and accurate recall of all the materials in the collection and the best tools or resources to use for any specific question (Gandhi, 2004; Lamont, 2004; Stover, 2004). As a result, reference librarians sometimes provide inaccurate information (Crowley \& Childers, 1971; Dewdney \& Ross, 1996; Hernon \& McClure, 1987; Olszak, 1993).

Although individual librarians may not always be accurate or remember the specific sources, there is, collectively, an enormous amount of information among all reference librarians. One way to benefit reference librarians would be to capture this communal knowledge and house it in one place for future use (Gandhi, 2004; Roberts, 2005). A process that could facilitate the capture and storage of this knowledge for later sharing is the process of managing knowledge, or knowledge management (KM). A KM tool is designed to aid organizations in determining how well they collect, store, retrieve, and share knowledge (De Jager, 1999; Gandhi, 2004; McGown, 2000). Although many organizations spend an inordinate amount of money purchasing these tools, they do not always use them correctly (Barth, 2004).

One example of a library tool that offers the possibility of capturing knowledge for later sharing and collaboration is QuestionPoint. QuestionPoint is a virtual reference service, that is, a reference service initiated electronically, often in real-time, where patrons employ computers or other Internet technology to communicate with reference staff without being physically present. QuestionPoint has a feature that can function as a KM tool. This feature is the knowledge base, which is built from various reference transactions (Markgren, Ascher, Crow, \& Lougee-Heimer, 2004). After students ask librarians questions through the online chat format, these questions, and their correct responses, are added to the knowledge base. Records may be added to the knowledge base, not only from the library users' online questions, but also from offline activities, such as walk-up questions, telephone reference questions, and any other source of questions or tacit knowledge, including informal discussions, guidelines, or rules of thumb.

Based on the manner by which records may be added, QuestionPoint has an extensive online knowledge base archive. Thus, whenever a question is repeated, the knowledge base could serve as the primary discovery source. The knowledge base facilitates knowledge retrieval because it is searchable by keyword and can be browsed by subject. It also permits the capture both of explicit and tacit knowledge and, therefore, facilitates knowledge exchange and knowledge creation. Because the system facilitates knowledge creation, knowledge retrieval, and knowledge sharing, it can be considered a KM tool (Huysman \& DeWit, 2002). Not all KM tools prove to be valuable nor fully utilized (Barth, 2004); therefore, the value of the Knowledge Base of QuestionPoint has yet to be fully established (Markgren et al., 2004). This study investigated the effectiveness of the Knowledge Base.

\section{Problem Statement}

No individual reference librarian can remember all sources, thus constituting a critical factor in the failure to always provide accurate information (Gandhi, 2004; Kim, 2000; Lamont, 2004). Research reveals that approximately $45 \%$ of all reference questions are answered incorrectly (Crowley \& Childers, 1971; Dewdney \& Ross, 1996; Hernon \& McClure, 1987; Olszak, 1993). Collectively, reference librarians possess a tremendous amount of knowledge (Dillon, 1999; Gandhi, 2004; Kim, 2000); a knowledge management tool could be critical in capturing the communal knowledge of librarians. QuestionPoint is a virtual reference service that features a Knowledge Base that can serve as a KM tool. Knowledge management tools, even when well designed, are not always effective because they sometimes fail to achieve their stated goal (Barth, 
2004). It is important to assess the quality of QuestionPoint for effective service of reference librarians.

\section{Goal Statement}

The goal of this research was to evaluate the value of the Knowledge Base tool offered by QuestionPoint in assisting the reference librarian in an academic library to be more effective in answering reference questions. An effective knowledge management system (KMS) supports the creation, transfer, and application of knowledge in an organization (Alavi \& Leidner, 2001). The KMS can be effective only if it is utilized to improve the application and reuse of knowledge. Companies that have prospered from KMS are not those that have implemented the technology, but those who have applied it (Tiwana, 2000). The effectiveness of QuestionPoint in improving reference service was measured by the application of the Knowledge Base by the reference librarians. If, through the use of the Knowledge Base of QuestionPoint, librarians used the Knowledge Base to serve as a memory bank and reduced duplication of research and time taken to answer a question, then QuestionPoint would be considered effective in improving reference services.

\section{Research Questions}

Four questions drove this study:

1. What is the extent of usage of QuestionPoint among reference librarians?

2. What impact does the use of the Knowledge Base of QuestionPoint have on the quality of service provided by librarians:

(a) in reducing duplication of workload?

(b) in reducing response time?

3. What do librarians perceive as the benefits of using the Knowledge Base of QuestionPoint?

4. What do librarians perceive as the problems of using the Knowledge Base of QuestionPoint?

\section{Literature Review}

Historical and empirical literature has been cited over the years and has shown that reference librarians provide accurate answers 55\% of the time. Crowley and Childers (1971) first illustrated this fact in two independent studies of medium-sized public libraries in which patrons asking questions of reference staff could expect correct answers 55\% of the time. Myers (1979) in a study exploring the effectiveness of telephone reference service reported an overall accuracy of $50.4 \%$. Hernon and McClure (1986), conducting a study of academic depository libraries, also indicated that reference librarians generally answered 50-60\% of questions correctly. Kaske and Arnold (2002), in an empirical study to investigate whether the 55\% rule held true for the new online chat reference service, reported an accuracy rate of 55\%. Most recently, Profeta (2006) examined e-mail reference services and reported $24 \%$ accuracy with source information.

Many reasons have been offered for ineffective reference service. Hernon and McClure (1983) tested if reference accuracy could be improved by a concentrated one-shot training of reference librarians. Their experimental study involved a pre-test, training, and a post-test procedure. The overall scores after the training declined rather than improved. In fact, the success rate "fell from $63.5 \%$ for the pre-test to $52.4 \%$ for the post-test" (p. 70 ). Because mistakes continue to be made by reference librarians, it is important that a solution be found. While training has been consid- 
ered an option for improvement, no one has investigated the use of knowledge management (KM) as an approach to improve effectiveness in a reference library on a national scale.

The literature offers many definitions for the phrase "knowledge management" (KM) (Davenport \& Prusak, 2000; Drucker, 1998; Nonaka \& Takeuchi, 1995). Davenport (1994) defined KM as the process of capturing, distributing, and effectively using knowledge. Gandhi (2004) and Rowley (1999) described KM as a concerted effort to capture critical knowledge, share information, and capitalize on the collective organizational memory to enhance decision-making, productivity, and creativity. Ackmerman, Pipek, and Wulf (2003), Bellaver and Lusa (2001), and Choo (2000) regarded $\mathrm{KM}$ as the method by which an organization can leverage the tacit and explicit knowledge of its employees, partners, and outside experts for the benefit of the organization. Smith (2001) suggested that employing KM facilitated greater efficiency within the organization and expressed the view that KM leveraged and reused the organization's existing resources, thus helping people in seeking out best practices. Beijerse (2000) supported this concept by asserting that by managing knowledge properly, an organization could improve efficiency.

In order to manage knowledge, organizations typically depend on knowledge management tools or systems (KMS). A KM tool or a knowledge management system (KMS) is designed to aid organizations in determining how well they collect, store, retrieve, and share knowledge (De Jager, 1999; Gandhi, 2004; McGown, 2000). Many researchers (Davenport \& Prusak, 2000; Hackbarth, 1998) have emphasized the importance of the KMS as a means of enhancing effectiveness. These researchers believed that organizations used KMS because these tools aided in preventing a repeat of previous errors, ensuring continuance of best practices, and drawing on the collective wisdom of current and previous employees (Nilakanta, Miller, \& Zhu, 2006). Damodaran and Olphert (2000) share this view by emphasizing that KMS are information systems that facilitate organizational learning by capturing important content and process or knowledge and making it available to employees as needed.

Supporting this view, Alavi and Leidner (2001) state that KMS refer to the use of modern technologies, such as the Internet, intranet, Lotus Notes, and software filters, to systematize, enhance, and expedite knowledge management. Davenport and Prusak (2000) agreeing with the other researchers, also assert that KMS are usually IT-based systems developed to support and enhance the organizational process of creation, storage/retrieval, and transfer of knowledge. These authors all point out, however, that although many KMS relied on IT as a viable enabler, IT did not apply to all facets of KM. Holzner and Marx (1990), like Alavi and Leidner, believed that KMS are multi-faceted and that effective KMS involved far more than just technology; an effective KMS "is also about the people who have been recruited, trained, developed and promoted within the organization" (p. 21). Jantz (2001) asserted that KM and the use of KMS could transform the library into a more efficient knowledge-sharing organization, because historically, librarians have maintained very informal question/answer "databases" in the form of shared paper card files and rolodexes for hard to find information and information of local importance (Nugent, 1995).

The literature revealed that other organizations have improved effectiveness by successfully sharing knowledge. Indeed, throughout the years, businesses have preserved their competitive edge because of the practice of knowledge sharing. In order to share knowledge, these businesses utilized KM and KMS. While not every KMS has been successful, the literature revealed the barriers that have caused failures and the factors that could contribute to successful KMS. According to the literature, the factors for a successful KMS are technology, culture, content, and process (Chong \& Choi, 2005)

\section{Technology}

Technology is an important factor in KMS and is usually the center of many KMS projects or initiatives (Alavi \& Leidner, 2001; Davenport, DeLong, \& Beers, 1998; O’Dell \& Grayson, 
1998). The appropriate type of technology depended on the size, need, and infrastructure of an organization (Alavi \& Leidner, 1999). Whatever technology is selected must be available and familiar to everyone (Davenport et al., 1998). Employees must feel that their tasks are made easier by using the technology. Technology has been shown to be an effective vehicle for knowledge sharing because it accelerates the process of both knowledge creation and knowledge transfer (O'Dell \& Grayson, 1998). Therefore, it is very important to select the appropriate technology for the KMS because, "if you wire it, they won't necessarily come" (O’Dell \& Grayson, 1998, p. 25). Barth (2004) also made this point, advising that building or providing a system didn't ensure usage, as borne out by the Pillsbury Company where the technology used for their KMS met all required specifications and was easy to use, yet employees failed to use it. McDermott and O'Dell (2000) sum it up when they stated that even though technology "may be interesting, easy to use, and has many features," (p. 76), it is possible that no one may use it. Technology, then, is important to KMS because it is the medium that facilitates the process of knowledge sharing. However, it is not the most important factor. An organization can invest in the most expensive and current technology yet fails in its endeavor to utilize KMS.

\section{Culture}

Davenport and Prusak (2000) emphasized that for a KMS to be successful, it was critical to have a knowledge-oriented culture; that is, a culture that encouraged and rewarded knowledge sharing. Knowledge sharing among individuals or groups within an organization is one of the most important facets of human interaction (Moon \& Park, 2002).

An absence of knowledge sharing could create inefficiencies in an organization. Davenport and Prusak (2000) point out that in many large corporations, employees solve the same problems repeatedly, duplicating effort because the knowledge of the previously solved problem has not been shared with the company. It was this recognition that in an organization there could be a vast untapped and unknown resource of knowledge, know-how, and best practices that caused the Chairman and CEO of Hewlett-Packard to lament, "I wish we knew what we know at HewlettPackard" (O'Dell \& Grayson, 1998, p. ix). Thus, a knowledge sharing culture is essential to successful KMS. The literature suggested that the culture of the reference librarians is to not willingly use KM tools. Jantz (2001), in discussing a study on the use of the Common Knowledge database (CKDB), a KM tool developed for his library, stated that the most challenging aspect was to get the reference librarians to always check the system as a reference source.

If an organization does not have a knowledge-supportive culture, then it must create such a culture or experience failure (Davenport \& Prusak, 2000; Garfield, 2006; O’Dell \& Grayson 1998). To be considered a knowledge-sharing culture, several factors must be present:

1. Full senior management support which could be reflected in supporting and enhancing employee training, providing incentives which are meaningful, such as recognition, merit raises, and having an HR policy that facilitates these procedures.

2. There should also be an issued mandate for use and disincentives for lack of use.

3. Every effort should be made to have employees buy-in to the project so they can feel empowered and willingly use the KMS, rather than feel forced to do so.

\section{Content}

Because knowledge is constantly changing, every KMS needs some degree of a knowledge structure to be successful (Davenport \& Prusak, 2000). The scope or content of the KMS must be analyzed carefully to ensure that it is not excessive. Sometimes companies attempt to collect and distribute all knowledge in the organization. This practice often leads to the creation of such an overwhelming database that employees find it impossible to identify useful information and, as a 
result, fail to utilize the system as demonstrated by Global Services, where employees all sent their contributions at the same time, resulting in a clogged and unwieldy system (Alavi \& Leidner, 2001; Kondo, 2006). It was, therefore, important, as Kondo pointed out, to analyze the knowledge carefully, determine what was important enough to affect the organization's effectiveness, and collect only that.

\section{Processes}

Alavi and Leidner (2001) defined KM processes as the activities or initiatives put in place to facilitate the communication, creation, sharing, and use of knowledge for the benefit of the organization. Processes also referred to the organization's general infrastructure or ways of doing things and the extent to which these acted as enablers of, or barriers to, good KM practice. Therefore, the process component involved looking at the organizational initiatives and infrastructure and whether they currently helped or hindered KM and the KM processes. O'Dell and Grayson (1998) emphasized that it was important to understand the workflow and identify the steps in the process that facilitated knowledge sharing, because even good intentions fail if there is no process for designing and managing change. Therefore, a map or flowchart or some other measure was essential to guide the organization's transition from the current state where knowledge was managed haphazardly or not at all, to the state where the organization had embraced internal transfer of knowledge as a core process aimed at providing clear and sustainable improvement in performance.

It was also important to identify and eliminate the steps or procedures that prohibited knowledge sharing, while at the same time, supporting and continuing the steps or procedures that contributed to successful knowledge sharing (Davenport \& Prusak, 2000). Failure to identify the procedures or priorities that succeeded while eliminating the procedures that fail could result in ineffectiveness. Many researchers (Chong \& Choi, 2005; Davenport \& Prusak, 2000; Moffet, McAdam, \& Parkinson, 2003; O'Dell \& Grayson, 1998) have stressed the importance of the workflow and recognized that the lack of integration between the KMS and the employees' work process could result in a loss of efficiency or a complete rejection of the KMS.

\section{QuestionPoint and Its Features}

QuestionPoint is a virtual reference service, often referred to as a Virtual Reference Desk (VRD). It is supported by global network of cooperating libraries worldwide, and comprised of the following features:

- Chat, a web-based feature that includes an instant messaging component that allows librarians to communicate with patrons in real time, synchronously. There is also a cobrowsing aspect which facilitates the sharing of electronic files or websites.

- Email. This feature is used to respond to patrons asynchronously. Patrons submit their request and responses are sent at a later date.

- Reporting tools. This feature can help the librarian manage both online and in-person reference transactions. Statistical reports based on the type and level of the reference activity could aid the librarian in making management decisions, demonstrate trends for funding proposals and measure library user satisfactions levels.

- Tracking. Librarians are able to track, file and manage the web-delivered questions from patrons.

- Knowledge base comprised of questions and answers from transactions. There is a local database as well as a global database. The content of the local database is based on local questions and answers, while the content of the global database is a database of questions and answers, added by member libraries. Both databases are searchable by subject or 
keyword. Each library can maintain a local Knowledge Base controlled by the subscribing library or library group. Libraries can also contribute to (and use) the Global Knowledge Base, a resource for reference support and discovery work, cooperatively built by all QuestionPoint members.

Librarians may add records to the local Knowledge Base not only from library users' online questions, but also from walk-up questions, telephone reference questions, and even from locallymaintained stumpers files. The local Knowledge Base becomes a key reference source customized to each library and its users' needs, saving time for the reference staff. Specialized local information or questions unique to local users grow into an invaluable archive. The local Knowledge Base tools allow staff to work more efficiently and to focus more energy on the new and complex questions not already available in the Knowledge Base. The library user also benefits from shortened response time and enhanced service.

As the Knowledge Base grows, its use as an effective reference discovery tool grows. And libraries can make both the Global and local Knowledge Bases available to users, right from the library web site.

The Knowledge Base of QuestionPoint is similar in principle and operation to OCLC's (Online Computer Library Center) successful cataloging system which has created the masterful cataloging database (O'Leary, 2003). In the case of the cataloging database system, all catalogers check the database before performing original cataloging and utilize the existing records, thus sharing knowledge, and effectively improving cataloging services (Gorman, 1998). This study will investigate the effectiveness of QuestionPoint as a KM tool. Alavi and Leidner (1999) listed reduced problem-solving time, faster results, and faster delivery among the benefits for an effective KMS. Thus, the effectiveness of QuestionPoint will be measured by its ability to help the librarians respond in a timely manner, eliminate duplication of effort, and serve as a memory bank.

\section{Research Methods}

The descriptive research design method was chosen to conduct this study. The study was accomplished using unobtrusive testing techniques, an analysis of the unobtrusive testing results, a survey instrument, and selected interviews. The first research question addressed the extent of usage of the Knowledge Base of QuestionPoint and was answered by the questionnaire and the interviews. The second research question dealt with the impact of the knowledge base on the quality of service. Both parts of this question were answered by both the survey and the unobtrusive study. The third and fourth research questions focused on the librarians' perceptions of the benefits and problems associated with QuestionPoint were addressed through the questionnaire and/or the interviews.

\section{Selection of the Population}

Academic libraries in the United States that use QuestionPoint comprised the population. According to the Library of Congress (personal communication, February 16, 2006), there are 97 academic libraries that use QuestionPoint. Since tests can raise suspicions when conducted within a small geographic area because of the possibility of librarians in neighboring towns communicating with each other, the use of a sample with a wider geographic spread is advisable (Crowley \& Childers, 1971). Thus, whenever several libraries were in the same geographic area or were part of the same university system, only one of those libraries was selected at random. This process produced a pool of 45 libraries that were neither in the same geographical area nor of the same university system. Of these available libraries, eight no longer used QuestionPoint, and three declined to participate; 34 libraries agreed to participate in the survey process. Twenty two of the libraries responded to the questionnaire, resulting in a $64 \%$ response rate. Because of a change in 
summer hours and the closure of the VRD service at some academic libraries during the summer months, only $28(82 \%)$ of the 34 libraries responded to questions during the unobtrusive testing process.

\section{Instrument Development}

A panel of six experts was assembled to establish the validity and reliability of all instruments used in the study. These experts included: a Ph.D. with a concentration in statistical analysis; an Ed.D. with a concentration in Instructional Technology; a Ph.D. with a concentration in Information Science and expertise in survey development; a Ph.D. with a concentration in Information Science with 25 years experience as an academic reference librarian, with 11 years providing asynchronous reference, and 9 years as a distance learning instructor; an ABD in Information Science with 32 years experience as an academic librarian and over 20 years as a library administrator; and a reference librarian with over 30 years of reference experience.

The scoring guidelines, the survey questions, and the unobtrusive reference questions were all sent to the expert panel for review for clarity and appropriateness. The library and information specialists on the expert panel reviewed the reference questions for difficulty, assessed the availability of resources to answer the questions, and confirmed that the answers selected were correct.

\section{Unobtrusive Testing}

Several studies have employed unobtrusive testing (Crowley \& Childers, 1971; Hernon \& McClure 1987; Myers, 1979; Profeta, 2006). Unobtrusive testing has been described as a "legitimate means of data collection and provides insights that are not easily obtained otherwise" (Hernon \& McClure, 1986, p. 37). It is a procedure that allows people to be observed in such a way that they do not realize that their actions are being recorded (Leedy \& Ormond 2001). This technique provides data not readily provided by other methods of research.

The questions used in an unobtrusive study must be typical of the questions that are actually received by the population that is being studied (Hernon \& McClure, 1987), not so difficult that only very experienced librarians with extensive, specialized subject knowledge would be able to provide an accurate answer (Paskoff, 1991), and the sources necessary to answer the questions should be readily available in any academic library (Hernon \& McClure, 1987; Paskoff 1991). The reference questions used in this study (see Appendix A) were characteristic of questions received in academic libraries through VRD. All of the questions were used from VRD questions actually sent to the researcher's institution. Questions specific to the researcher's institution, such as hours of service, specific holdings, or availability of services were eliminated. None of the questions was deemed by the expert panel to be difficult to understand, but the questions were of increasing difficulty (White, Abels, \& Kaske, 2003). Each of the questions selected was researched, and basic sources that held the correct answers were identified. Each library owned, subscribed to, or had access to the resources that facilitated an accurate response to each of the six questions (Hernon \& McClure, 1987). The library and information specialists on the expert panel were asked to review the questions and individually provide answers. These experts then collectively confirmed that the answers selected were correct.

The unobtrusive testing process incorporated a total of six questions: two ready reference questions, two research questions, and two bibliographic citation questions, in accordance with the accepted reference categories (Garnsey \& Powell, 2000). For each question selected, a background story was written to provide authenticity for the request, in accordance with Elzy, Nourie, Lancaster, and Joseph (1991) and Ward, Mervan, Loving, and Kronen (2002/2003) who stressed the need for a cover story to protect the secrecy of the study. The researcher made every effort to ensure a fair distribution of questions by making sure that every library received questions at dif- 
ferent times during the day and on weekends. The contact with the libraries spread across the hours and days of the week in a random way, allowing all libraries to receive questions during hours of both weak and strong staffing (Crowley \& Childers, 1971). In order to determine if the Knowledge Base of QuestionPoint served as a memory bank or reduced duplication the two research questions were repeated.

All libraries received the same six questions. Both Crowley (Crowley \& Childers, 1971) in his pioneering study, and Childers (1980) in his follow-up study, asked the same questions of all the libraries they tested. To assess duplication the researcher repeated the two research questions (Hernon \& McClure, 1983).

\section{Survey and Interview Script}

The review of the literature helped to identify an appropriate survey instrument, one that was used to evaluate the Missouri Statewide Bibliographic Database on CD-ROM (Niemeyer 1990). This instrument had some useful features but had to be modified to meet the specific requirements of the research. The researcher validated this modified survey (See Appendix B) through expert panel review. The survey was delivered by SurveyMonkey, a web-based survey instrument.

The researcher randomly called 10 reference librarians who did not respond to the survey and tried to set up an appointment for an interview. The same survey questions were given to the nonresponders to ensure consistency in the questions asked and to ensure that the non-responders did not represent "a biased group who [would have] answered the questionnaire in a markedly different manner than the responding group" (Gall, Gall \& Borg, 1999, p. 434). Four of the ten were available to be interviewed, resulting in a total of 22 libraries surveyed or interviewed, making an overall 65\% response rate. Descriptive statistics including percentages, means, and standard deviations, were used to describe the sample.

\section{Data Collection}

The results of the unobtrusive testing and the responses to the questionnaire and the interviews constituted the data collected for this study. Although a form of qualitative research, descriptive research design often contains a mix of both qualitative and quantitative evidence (Creswell 2003; Gorman \& Clayton 2005). Therefore, in this study, both qualitative and quantitative data were collected.

\section{Findings}

This study consisted of a survey, interviews, and an unobtrusive study. From the pool of 34 qualified and willing libraries, 22 participated in the survey and interviews and 28 were sent six questions unobtrusively through the use of six proxies.

\section{Research Question 1: What is the extent of usage of the Knowledge Base of QuestionPoint by reference librarians?}

Based upon the survey responses, very little or no use was made of the Knowledge Base of QuestionPoint. Twenty-one (96\%) of the libraries did not use the Knowledge Base, but performed original research. Only one library used the Knowledge Base of QuestionPoint and that use was reported to be less than $5 \%$ of the time, performing original research more than $95 \%$ of the time. The feature most commonly used was the Chat feature. 


\section{Research Question 2a: What impact does the use of the Knowledge Base have on the quality of service provided by the Librarians in Reducing Duplication}

From the responses on the questionnaire, it was revealed that, generally, reference librarians performed original research approximately $95 \%$ of the time rather than use the Knowledge Base of QuestionPoint. Occasionally, one library used the Knowledge Base of QuestionPoint, and this use occurred less than $5 \%$ of the time. The questionnaire also revealed that the Knowledge Base of QuestionPoint did not serve as a memory bank. Twenty-one (95\%) of the libraries said that the Knowledge Base did not reduce duplication (see Table 1). Twenty-one (95\%) of the libraries said that the Knowledge Base did not serve as a memory bank (See Table 2).

Repeating two of the unobtrusive questions also revealed that the lack of use of the Knowledge Base of QuestionPoint affected duplication. Questions four and five were resubmitted exactly as they were previously asked. In the case of Question four, there was no relationship between the responses provided the second time and the responses provided the first time, as none of the libraries provided the identical response both times. In the case of Question five, only one library provided the exact response when repeated. Additionally, there was a possible response to Question five already existing in the Knowledge Base, yet none of the libraries provided this response. It is clear that there was a high level of duplication with only one library providing the exact response on one occasion

Table 1. Librarians' Responses to Duplication of Workload

\begin{tabular}{|l|l|l|l|l|l|l|}
\hline & & $\begin{array}{l}\text { Strongly } \\
\text { Disagree }\end{array}$ & Disagree & Neutral & Agree & $\begin{array}{l}\text { Strongly } \\
\text { Agree }\end{array}$ \\
\hline (a) & $\begin{array}{l}\text { Duplication is reduced because the } \\
\text { Knowledge Base of QuestionPoint is } \\
\text { used instead of repeatedly performing } \\
\text { original research }\end{array}$ & $13(59 \%)$ & $8(36 \%)$ & $1(5 \%)$ & & \\
\hline (b) & $\begin{array}{l}\text { Peers with specialized expertise con- } \\
\text { tribute to the Knowledge Base of Ques- } \\
\text { tionPoint and this reduces the need for } \\
\text { every librarian to research the same } \\
\text { question }\end{array}$ & $14(64 \%)$ & $8(36 \%)$ & & & \\
\hline (c) & $\begin{array}{l}\text { Using the Knowledge Base supplements } \\
\text { the time that new librarians spend with } \\
\text { mentors. }\end{array}$ & $18(82 \%)$ & $4(18 \%)$ & & & \\
\hline (d) & $\begin{array}{l}\text { Using the Knowledge Base supplements } \\
\text { training for new librarians }\end{array}$ & $21(95 \%)$ & $1(5 \%)$ & & & \\
\hline
\end{tabular}


Table 2. Librarians' Response to the Knowledge Base as a Memory Bank

\begin{tabular}{|l|l|l|l|l|l|l|}
\hline & & $\begin{array}{l}\text { Strongly } \\
\text { Disagree }\end{array}$ & Disagree & Neutral & Agree & $\begin{array}{l}\text { Strongly } \\
\text { Agree }\end{array}$ \\
\hline (a) & $\begin{array}{l}\text { Librarians at my institution enter offline } \\
\text { transactions into the Knowledge Base of } \\
\text { QuestionPoint and this serves as the } \\
\text { institutional memory. }\end{array}$ & $15(68 \%)$ & $6(27 \%)$ & $1(5 \%)$ & & \\
\hline (b) & $\begin{array}{l}\text { Librarians maintain consistency by al- } \\
\text { ways reviewing the Knowledge Base } \\
\text { before responding to a question re- } \\
\text { ceived through QuestionPoint. }\end{array}$ & $17(77 \%)$ & $5(23 \%)$ & & & \\
\hline (c) & $\begin{array}{l}\text { The shared knowledge on the Knowl- } \\
\text { edge Base of QuestionPoint serves as a } \\
\text { memory bank for librarians. }\end{array}$ & $19(86 \%)$ & $3(14 \%)$ & & & \\
\hline (d) & $\begin{array}{l}\text { When peers with specialized expertise } \\
\text { contribute to QuestionPoint, it aids in } \\
\text { providing access to additional re- } \\
\text { sources. }\end{array}$ & $19(86 \%)$ & $3(14 \%)$ & & & \\
\hline
\end{tabular}

\section{Research Question 2b: What impact does the use of the Knowledge Base have on the quality of service provided by the Librarians in Reducing Response Time?}

As questions were submitted unobtrusively, the researcher timed each transaction performed by each library, then averaged the time. The literature suggest that for virtual reference transactions, the hold time, that is the time the patron waits to be acknowledged, averages between 40 and 50 seconds while the actual service time - the time it takes the librarian to complete the reference transaction and provide an answer averages between 11:57minutes and 27:59 minutes (Connaway $\&$ Radford, 2006; Patterson, 2001). In this research, the hold time fell into a similar pattern and averaged 43 seconds. The actual service time, upon which this research will focus, portrayed overall, a mean service duration of 12:53minutes and a median service duration of 9:37minutes.

When Questions 4 was asked the first time, it took the libraries an average of 10.5 minutes when it was repeated, it took an average of 12 minutes. When question 5 was asked the first time, it took 12.4 minutes, but when it was repeated, it took 13.7 minutes. Repeating questions 4 and 5 permitted the comparison of response time and allowed the researcher to assess if there was a reduction in time when the question was repeated. The results showed that when a question was asked the second time it did not reduce time.

\section{Research Question 3: What do librarians perceive as the benefits of using the Knowledge Base of QuestionPoint?}

Three main reasons were identified as benefits of using the Knowledge Base of QuestionPoint. Seventeen libraries (77\%) believed that the Knowledge Base of QuestionPoint could facilitate knowledge sharing. Eight (36\%) believed that it could avoid duplication; four (18\%) believed that it could save time if someone asked the same question. During the interview, all four librarians interviewed made the point that while they did not use the Knowledge Base, they believed that 
the benefits cited represented what they perceive could beneficial had they used the Knowledge Base. Other specific responses included:

- "It could facilitate knowledge sharing."

- "It could be useful for future use."

- "It could avoid duplication."

- "It could save time if someone else asked the same question."

- "It could make answering questions easier."

- "It could be useful as it could make answering questions easier."

- "It could be useful to have knowledge accumulation in one place."

- "It could prevent the need to repeat the research."

Thus, in theory, the reference librarians understood the concept of the knowledge base and supported the concept of knowledge sharing. Three of the librarians interviewed were eager to point out that reference librarians shared knowledge all the time. They did this informally and orally, sharing tacit as well as explicit knowledge - they just did not readily record this knowledge in a database or make use of a KM tool. When pushed for a reason, one librarian said, "Um, I dunno, we're too busy, I guess. In the reference department, we are always under the gun." Another reference librarian opined, "I think each reference librarian believe[s] that she can do a better job of responding to a query and didn't see the need to use the Knowledge Base."

\section{Research Question 4: What do librarians perceive as the problems of using the Knowledge Base of QuestionPoint?}

Through both the questionnaire and the follow-up interview, the reference librarians were very vocal in identifying the problems of QuestionPoint. There were several reasons given for performing original research in lieu of utilizing the Knowledge Base. Four (19\%) libraries said that the Knowledge Base of QuestionPoint is not user-friendly; 8 (38\%) said finding content in the Knowledge Base is difficult; 15(68\%) said it required an extra step; 10 (48\%) said using the Knowledge Base was time-consuming, and 5(24\%) said using the Knowledge Base is not required by superiors. Other responses included:

- "I never think of using the Knowledge Base."

- "Training did not emphasize the use of the Knowledge Base."

- "Training was inadequate."

- "The use and value of the Knowledge Base is not well known."

- "Finding information through the content was very difficult."

- "The content was neither useful nor relevant."

\section{Conclusions and Recommendations for Further Research}

According to the literature, one of the most critical reasons for KM failure is lack of use (Barth, 2004) because no use or inconsistent use of any KMS renders that tool ineffective (Alavi \& Leidner, 2001; Davenport et al., 1998; O'Dell \& Grayson, 1998). The results showed insignificant use of the Knowledge Base of QuestionPoint. No use or low use of the tool is attributed to 
several factors including the technology, the organization's culture, the content or the process (Alavi \& Leidner, 2001; Chong \& Choi, 2005; Davenport \& Prusak, 2000). The following discussion shows the relationship between these factors and the Knowledge Base of QuestionPoint.

\section{Technology}

The Knowledge Base of QuestionPoint met technological standards and was capable of serving as a KM tool (Markgren et al., 2004). It could facilitate consistency and eradicate duplication. It was also readily accessible to all. However, adequate training was not provided for the Knowledge Base feature. From the survey, all $22(100 \%)$ of the libraries participated in some form of training. Nineteen (86\%) of the libraries believed that the training was adequate for the use of QuestionPoint's Chat component, but 16 (73\%) believed that the training was inadequate for the effective use of the Knowledge Base of QuestionPoint.

\section{Culture}

The culture did not really support the system. In the case of the Knowledge Base of QuestionPoint, the survey revealed that although management paid for the QuestionPoint technology, none of the libraries mandated or even encouraged the use of the Knowledge Base. In order to encourage use, meaningful incentives such as merit raises or peer recognition should be implemented both for the reference librarians who contribute quality responses to the Knowledge Base and for those who review the Knowledge Base prior to responding to a virtual reference question. The librarians interviewed revealed that OCLC offered the incentive of reduced rates if the Knowledge Base was used, yet management did not find a way to enforce or encourage use in order to justify the discount. "I felt guilty not using it because of the discount," one reference librarian confessed during the interview.

\section{Content}

The content of the Knowledge Base of QuestionPoint was poorly managed. For a KMS to be successful, it is important to review and update the content, check for quality responses, and ensure that the responses provided are correct so that when similar or the same questions are asked, accurate answers can be provided. The answers must also be reviewed constantly for currency and updated when necessary. Careful attention must be paid to the quality of the responses, so that if the question is repeated, an accurate response is provided in the future, even if it was not previously provided. It is pointless to repeat a mediocre or inaccurate response. It is clear from the unobtrusive testing that the content of the Knowledge Base of QuestionPoint was not well managed.

This lack of management was demonstrated when question five was repeated. The exact response was provided the second time by the library that claimed to use the Knowledge Base less than 5\% of the time. If we are to assume that the Knowledge Base was used, it is unfortunate that the response given the first time was partially correct and documented. As a result, the response provided the second time also was partially correct and documented. This result would suggest that if the Knowledge Base was used, the area of quality control of the content was neglected.

Further evidence was revealed that the content of the Knowledge Base was not maintained. For example, two questions very similar to Question five could be found in the Knowledge Base. However, the responses were contributed to the content in November, 2005. The data and the statistics provided were neither accurate nor current. The questionnaire revealed that the reference librarians had no confidence in the content of the Knowledge Base, since 10(38\%) believed that the content was difficult to find; while an additional $2(9 \%)$ felt that the content was not relevant to the needs of their library patrons. It could be argued that the failure of the librarians to consistently contribute to and maintain the Knowledge Base was the reason for its inadequacy. Thus the 
Knowledge Base of QuestionPoint could be more reliable if it was used and maintained by the reference librarians.

\section{Process}

Additionally, using the Knowledge Base must be a natural part of the process of the workflow. The study revealed that using the Knowledge Base of QuestionPoint was not a seamless part of the workflow and was not integrated into the work process. As a result, using the Knowledge Base was perceived as tedious, a waste of time, and an extra step. Many researchers have recognized this absence of integration as a critical factor that leads to the failure of the KM tool (Chong \& Choi, 2005; Davenport \& Prusak, 2000; Moffet et al., 2003; O’Dell \& Grayson, 1998).

\section{Further Research}

The effectiveness of the Knowledge Base of QuestionPoint in improving reference service was measured by the application of the Knowledge Base by the reference librarians. If the reference librarians used the Knowledge Base of QuestionPoint and through its use these librarians improved timeliness and reduced duplication, then QuestionPoint would be considered effective in improving reference services. The Knowledge Base of QuestionPoint was not used, response time was not improved, and duplication of effort was revealed. Thus the lack of use of the Knowledge Base of QuestionPoint and its inability to improve timeliness or duplication rendered it ineffective as a KM tool.

For several years, reference services in libraries have been inadequate and continue to be so. It has been shown that KM can improve services. The Knowledge Base of QuestionPoint was not used and thus proved to be ineffective. Reference Librarians should expend effort and resources into developing Knowledge Management Systems designed to provide effective services. The question of how the information professional meets this challenge demands urgent study and solution. After the appropriate KMS is developed, this study should be replicated using another group of libraries such as public libraries, special libraries, or even community college libraries. This will help determine if in these other settings librarians are more likely to utilize KM since they may have the same questions on a more frequent basis.

This research also suggests that there is an inherent culture of reluctance on the part of reference librarians to use a KM tool. Thus, further research should also be conducted to explore the factors affecting the reluctance of reference librarians to use a KM tool. Research could determine the reason for the reluctance and possibly offer a solution. Since there seems to be a problem with the content of the Knowledge Base of QuestionPoint, a viable research may be to assess the breadth and depth of the content of this Knowledge Base. Such a research can be achieved by developing a list of reference questions and directly accessing the Knowledge Base of QuestionPoint to determine what kind of responses would be received.

As we look to the future, it may be helpful to assess whether the new generation of librarians are being prepared to recognize the value of knowledge management. It may therefore be a useful research to review the programs of Library Schools to see if KM forms a significant component of the curriculum. The important thought to keep in mind is that a good librarian knows about the existing resources, but a great librarian, helps to establish content, create resources and share the knowledge. Effective use of a KMS could help create a future generation of great librarians. 


\section{References}

Ackerman, M., Pipek, V., \& Wulf, V. (2003). Sharing expertise: Beyond knowledge management. Cambridge, MA: MIT Press.

Alavi, M. (2000). Managing organizational knowledge. In R.W. Zmud (Ed.), Framing the domains of IT management. Cincinnati, OH: Pinnaflex Educational Resources.

Alavi, M., \& Leidner, D. (1999). Knowledge management systems: Issues, challenges, and benefits. Communications of the Association for Information Systems, 1(7). Retrieved November 22, 2005 from http://cais.isworld.org/articles/1-7/article.htm

Alavi, M., \& Leidner, D. (2001). Knowledge management and knowledge management systems: Conceptual foundations and research issues. MIS Quarterly, 25(1), 107-136.

Barth, S. (2004). KM horror stories. KM, 3(10), 36-40.

Beijerse, R. P. (2000). Knowledge management in small and medium-sized companies: Knowledge management for entrepreneurs. Journal of Knowledge Management, 4(2), 162-179.

Bellaver, R. F., \& Lusa, J. M. (2001). Knowledge management strategy and technology. Norwood, MA: Artech House.

Childers, T. (1980). The test of reference. Library Journal, 105, 924-928.

Chong, S., \& Choi, Y. S. (2005). Critical factors in the successful implementation of knowledge management. Journal of Knowledge Management Practice. Retrieved May 5, 2006, from http://www.tlainc.com/articl90.htm

Choo, C. W (2000). The knowing organization: How organizations use information to construct meaning, create knowledge, and make decisions. New York: Oxford University Press.

Connaway, L. C., \& Radford, M. L. (2006). Seeking synchronicity: Evaluating virtual reference transcripts. Paper presented at the QuestionPoint Users Group Meeting, June 25, 2006, New Orleans, Louisiana.

Creswell, J. W. (2003). Research design: Qualitative, quantitative and mixed methods approach (2nd ed.). Thousand Oaks: Sage Publications.

Crowley, T., \& Childers T. (1971). Information service in public libraries: Two studies. Metuchen, N.J.: Scarecrow.

Damodaran, L., \& Olphert, C. W. (2000). Barriers and facilitators to the use of knowledge management systems. Behavior and Information Technology, 19(6), 405-413.

Davenport, T. H. (1994, March/April). Saving ITU's soul: Human-centered information management. Harvard Business Review, 54-62.

Davenport, T. H., DeLong, D. W., \& Beers, M. C. (1998, Winter). Successful knowledge management projects. Sloan Management Review, 39(2), 43-57.

Davenport, T. H. \& Prusak, L. (2000). Working knowledge: How organizations manage what they know. Boston: Harvard Business School Press.

De Jager, M. (1999). The KMAT: Benchmarking knowledge management. Library Management, 20(7), 367-368.

Dewdney, P., \& Ross, C. S. (1996). Flying a light aircraft: Reference service evaluation from a user's viewpoint. Retrieved April 14, 2005, from www.ala.org/ala/rusa/rusapubs/rusq/specialfeatures/rspawardw

Dillon, M. (1999). Knowledge management opportunities for libraries and universities. The Library and Information Science Annual, 7, 3-11.

Drucker, P. F. (1998). The coming of the new organization. In Harvard Business Review in Knowledge Management (pp. 1-20). Boston: Harvard Business Review. 
Elzy, C., Nourie, A., Lancaster, F. N., \& Joseph, K. (1991). Evaluating reference services in a large academic library. College \& Research Libraries, 52, 454-465.

Gall, J., Gall, M., \& Borg, W. (1999). Applying educational research: A practical guide. New York: Longman.

Gandhi, S. (2004). Knowledge management and reference services. The Journal of Academic Librarianship, 30(5), 368-381.

Garfield, S. (2006). Ten reasons why people don't share their knowledge. KM Review, 9(2), 10-11.

Garnsey, B.A., \& Powell, R. R. (2000). Electronic mail reference services in the public library. Reference \&User Services Quarterly, 39, 245-254.

Gorman, M.C. (1998). Cataloging with copy methods for increasing productivity. Englewood, CO: Libraries Unlimited.

Gorman, G. E., \& Clayton, P. (2005). Qualitative research for the information professional (2nd ed.). London: Facet Publishing.

Hackbarth, G. (1998). The impact of organizacional memory on IT systems. In E. D. Hoadley \& I. Benbasat (Eds.), Proceedings of the 4th Ameritas Conference on Information Systems, 588-590.

Hernon, P., \& McClure, C. (1983). Improving the quality of reference service for government publications. Chicago: American Library Association.

Hernon, P., \& McClure, C. (1986). Unobtrusive reference testing: The 55 percent rule. Library Journal, $111,37-41$.

Hernon, P., \& McClure, C. (1987). Unobtrusive testing and library reference services. Norwood, NJ: Ablex.

Holzner, B., \& Marx, J. (1990). The knowledge application: The knowledge system in society. Boston: Allyn-Bacon.

Huysman, M. H.. \& deWit, D. (2002). Knowledge sharing in practice. Boston: Kluwer Academic Press.

Jantz, R. (2001). Knowledge management in academic libraries: Special tools and processes to support information professionals. Reference Services Review, 29(1), 33-39.

Kaske, N., \& Arnold, J. (2002). Unobtrusive evaluation of online real time library reference service. Retrieved March 15, 2007, from http://www.lib.umd.eu/groupsdigref/kaskearnold.unobtrusive.html

Kim, S. (2000). The roles of knowledge professionals for knowledge management. Inspel, 34(1), 1-8.

Kondo, F. (2006). Five steps to a successful management initiative. IT world. Retrieved Oct., 5, 2005 from http://www.itworld.com/App/236/060131km

Lamont, J. (2004, January). Knowledge management at your service: New solutions and sources for librarians. Searcher: The Magazine for Database Professionals, 12(1), 57-61.

Leedy, P. D., \& Ormond, J. E. (2001). Practical research: planning and design (7th ed.). Upper Saddle River, NJ: Prentice-Hall.

Markgren, S., Ascher, M. T., Crow, S. J., \& Lougee-Heimer, H. (2004). Asked and answered online: How two medical libraries are using OCLC's QuestionPoint to answer reference questions. Medical Reference Services, 23(1), 13-28.

McDermott, R., \& O’Dell, C. (2000). Overcoming cultural barriers to sharing knowledge. Journal of Knowledge Management, 5(1), 76-85.

McGown, K. A. (2000). Knowledge management in the twenty-first century: The role of the academic librarian. Digital Dissertations. Proquest Database. (UMI No. 9980867).

Moffet, S., McAdam, R., \& Parkinson, S. (2003). An empirical analysis of knowledge management applications. Journal of Knowledge Management, 7(3), 6-26. 
Moon, H. K., \& Park, M. S. (2002). Effective reward systems for knowledge sharing. Knowledge Management Review, 4(6), 22-25.

Myers, M. J. (1979). The effectiveness of telephone reference/ information services in academic libraries in the southeast. Digital Dissertations. Proquest Database. (UMI No. 8008614).

Niemeyer, M. D. (1990). Evaluation of the Missouri statewide bibliographic database on CD-ROM (Report No. IR 053 642). Warrensburg: Central Missouri State University. (ERIC Document Reproduction Service No. ED36 094).

Nilakanta, S., Miller, L., \& Zhu, D. (2006). Organizational memory management: Technological and research issues. Journal of Database Management, 17(1), 85-94.

Nonaka, I., \& Takeuchi, H. (1995). The knowledge-creating company: How Japanese companies create the dynamics of innovations. New York: Oxford University Press.

Nugent, C. R. (1995). Rolodex facilitates reference. College and Undergraduate Libraries, 2(2), 129-131.

O’Dell, C., \& Grayson, C. J. (1998). If only we knew what we know: Identification and transfer of internal best practices. California Management Review, 40(3), 154-165.

O'Leary, M. (2003). QuestionPoint fortifies libraries in Internet age. Online, 27(3). Retrieved March 25, 2005 from http://infotoday.com/online/may03/Oleary.shtm

Olszak, L. (1993). Mistakes and failures at the reference desk. Retrieved April 14, 2005, from http://www.ala.org/ala/rusa/rusapubs/rusq/specialfeatures/rspawardw

Paskoff, B.M. (1991). Accuracy of telephone reference service in health sciences libraries. Bulletin of the Medical Library Association, 79, 182-188.

Patterson, R. (2001). Live virtual reference: More work and more opportunity. Reference Services Review, 29(3), 204-209.

Profeta, P. C. (2006). Effectiveness of asynchronous reference services for distance learning students within Florida's community college system. Digital Dissertations. Proquest Database. (UMI AAT 3212018).

Prokopiadou, G., Papatheodorou, C., \& Moschopoulos, D. (2004). Integrating knowledge management tools for government information. Government Information Quarterly, 21, 170-198.

Roberts, G. (2005). Groupware as a knowledge repository: Computers in small libraries. Computers in Libraries, 25(4), 29-31.

Rowley, J. (1999). What is knowledge management? Library Management, 20(8), 416.

Smith, E.A. (2001). The role of tacit and explicit knowledge in the workplace. Journal of Knowledge Management, 5(4), 311-321.

Stern, D. (2003). New knowledge management systems: The implications for data discovery, collection development, and the changing role of the librarian. Journal of the American Society for Information Science, 54(12), 1138-1140.

Stover, M. (2004). Making tacit knowledge explicit: The ready reference database as codified knowledge. Reference Services Review, 32(2), 164-173.

Tiwana, A. (2000). The knowledge management toolkit: Practical techniques for building knowledge management systems. Upper Saddle River, NJ: Prentice-Hall.

Ward, J., Mervan, D., Loving, M., \& Kronen, S. (2002/2003). Going it alone: Can a small/medium-sized library manage online reference? The Reference Librarian, 79/80, 311-322.

White, D. M., Abels, E. G., \& Kaske, N. (2003). Evaluation of chat reference service quality. D-Lib Magazine, 9(2). Retrieved May 4, 2006 from www.dlib.org/dlib/february03/white/02white.html 


\section{Appendix A: Questions for the Unobtrusive Study}

1. Where can I find information on Celebrex?

2. I need help in setting up this citation according to APA: The information I have is Title: Digital mammography may improve breast cancer diagnosis. AORN Journal, Jan 2007, vol. 85 , issue 1,90 .

3. I am trying to find an article written by Cynthia Epstein. The title is Great Divides: the cultural, cognitive and social bases of the global subordination of women. I can't remember where I found it, but I have to find it and cite it. Can you help me find it and can you help me cite it MLA?

4. What was the population of Aruba in 2001 and what is their official language?

5. How many people from Louisiana died in the hurricane Katrina? How many of them were children under 16 years old?

6. Where can I find information on vertigo? Is it a serious disease? And is it contagious?

\section{Appendix B: QuestionPoint Questionnaire}

Please respond to the following questions about the use of QuestionPoint (QuestionPoint) in your library. Check or respond to each question appropriately.

\section{Demographic Information}

1. Title of person completing questionnaire:

2. Size of library book collection:

Under 25,000

$25,001-50,000$

$50,001-100,000$

$100,001-250,000$

Over 250,000

3. How long has your library used QuestionPoint?

Less than 1 year

$1-3$ years

4-6 years

Over 6 years

\section{Use of the Features of QuestionPoint}

4. Which features of QuestionPoint do you use?

Chat reference

Knowledge Base

Reporting feature

Track questions

Other

5. Is there a mandate from your administrator to use any specific feature of QuestionPoint?

Yes

No 
6. If there is a mandate which feature/s is/are mandatory

Chat reference

Knowledge Base

Reporting feature

Track questions

Other

7. If there is no mandate, which features do you use?

Chat reference

Knowledge Base

Reporting feature

Track questions

Other

\section{Use of the Knowledge Base of QuestionPoint}

8. When responding to a reference question, do your librarians use the Knowledge Base of QuestionPoint, or do they perform original research?

Use Knowledge Base Perform original research

9. If your librarians do not always first review the Knowledge Base, how often do they use this feature?

$$
\begin{aligned}
& \text { Not at all } \\
& \text { Less than 5\% } \\
& 5 \%-25 \% \\
& 26 \%-50 \% \\
& 51 \%-75 \% \\
& 76 \%-90 \% \\
& 91 \%-99 \% \\
& 100 \%
\end{aligned}
$$

10. If the librarians performed original research, what percentage of the time did they perform it?

\begin{tabular}{ll} 
Not at all & \\
Less than 5\% & \\
$5 \%-25 \%$ & \\
$26 \%-50 \%$ & \\
$51 \%-75 \%$ & \\
$76 \%-90 \%$ & \\
$91 \%-99 \%$ & \\
$100 \%$ & \\
\hline
\end{tabular}

11. The librarians DO NOT use the Knowledge Base because:

(Please Check all that apply)

The Knowledge Base of QuestionPoint is not user-friendly

Finding relevant content is difficult

Using the Knowledge Base is time-consuming

Using the Knowledge Base is not required by superiors

Other (please specify)

12. What do you perceive as the benefits of using the Knowledge Base

13. What do you perceive as the problems of using the Knowledge Base? 


\section{Training}

14. Did your librarians participate in training to use QuestionPoint?

Yes

No

15. If yes, who provided the training?

QuestionPoint

Internal trainer, trained by QuestionPoint

Service provided by QuestionPoint

Other

16. Was the training adequate for the effective use of QuestionPoint?

Yes _ No

17. Was the training adequate for the effective use of the Knowledge Base of QuestionPoint?

Yes

No

\section{Culture of the Organization}

18. Organizational Culture:

Please make the appropriate selection: Strongly Disagree (SD); Disagree (D);

Neutral (N) Agree (A); Strongly Agree (SA)

\begin{tabular}{|c|c|c|c|c|c|c|}
\hline & & SD & $\mathrm{D}$ & $\mathrm{N}$ & A & SA \\
\hline (a) & $\begin{array}{l}\text { Reference Librarians are required to use the Knowl- } \\
\text { edge Base }\end{array}$ & & & & & \\
\hline (b) & $\begin{array}{l}\text { Reference Librarians are rewarded for using the } \\
\text { Knowledge Base }\end{array}$ & & & & & \\
\hline (c) & $\begin{array}{l}\text { Reference Librarians are penalized for not using the } \\
\text { Knowledge Base }\end{array}$ & & & & & \\
\hline (d) & $\begin{array}{l}\text { Reference Librarians are recognized for using the } \\
\text { Knowledge Base }\end{array}$ & & & & & \\
\hline (e) & $\begin{array}{l}\text { Knowledge sharing responsibilities are a normal part } \\
\text { of everyone's roles, responsibilities, and duties within } \\
\text { the reference department }\end{array}$ & & & & & \\
\hline (f) & $\begin{array}{l}\text { Sharing knowledge and collaborating with colleagues } \\
\text { improve performance }\end{array}$ & & & & & \\
\hline
\end{tabular}

\section{Duplication}

19. Duplication of Workload

Please make the appropriate selection: Strongly Disagree (SD); Disagree (D);

Neutral (N) Agree (A); Strongly Agree (SA)

\begin{tabular}{|l|l|l|l|l|l|l|}
\hline & & SD & D & N & A & SA \\
\hline (a) & $\begin{array}{l}\text { Duplication is reduced because the Knowledge Base of Ques- } \\
\text { tionPoint is used instead of repeatedly performing original re- } \\
\text { search }\end{array}$ & & & & \\
\hline (b) & $\begin{array}{l}\text { Peers with specialized expertise contribute to the Knowledge } \\
\text { Base of QuestionPoint and this reduces the need for every li- } \\
\text { brarian to research the same question }\end{array}$ & & & & & \\
\hline (c) & $\begin{array}{l}\text { Using the Knowledge Base supplements the time that our new } \\
\text { librarians spend with unfamiliar resources. }\end{array}$ & & & & \\
\hline
\end{tabular}




\begin{tabular}{|l|l|l|l|l|l|l|}
\hline (d) & $\begin{array}{l}\text { Using the Knowledge Base supplements training for our new } \\
\text { librarians. }\end{array}$ & & & & \\
\hline (e) & $\begin{array}{l}\text { Reference Librarians gain tacit knowledge by reviewing the } \\
\text { Knowledge Base }\end{array}$ & & & & \\
\hline
\end{tabular}

\section{$\underline{\text { Memory Bank }}$}

20. Memory Bank

Please make the appropriate selection: Strongly Disagree (SD); Disagree (D);

Neutral (N) Agree (A); Strongly Agree (SA)

\begin{tabular}{|l|l|l|l|l|l|l|}
\hline & & SD & D & N & A & SA \\
\hline (a) & $\begin{array}{l}\text { Librarians at my institution enter offline transactions into } \\
\text { the Knowledge Base of QuestionPoint and this serves as } \\
\text { the institutional memory. }\end{array}$ & & & & \\
\hline (b) & $\begin{array}{l}\text { Librarians maintain consistency by always reviewing the } \\
\text { Knowledge Base before responding to a question re- } \\
\text { ceived through QuestionPoint }\end{array}$ & & & & & \\
\hline (c) & $\begin{array}{l}\text { The shared knowledge on the Knowledge Base of Ques- } \\
\text { tionPoint serves as a memory bank for librarians. }\end{array}$ & & & & \\
\hline (d) & $\begin{array}{l}\text { When peers with specialized expertise contribute to } \\
\text { QuestionPoint, it aids in providing access to additional } \\
\text { resources. }\end{array}$ & & & & \\
\hline
\end{tabular}

Thank You for completing this Questionnaire! 


\section{Biographies}

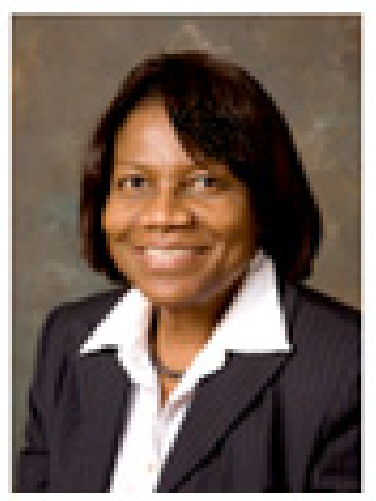

Dr. Lynette Ralph obtained a BA degree from the University of the West Indies (U.W.I.), an MS (Library \& Information Science) from Pratt Institute, an MPA from University of Baltimore, and a Ph.D. in Information Science from Nova Southeastern University.

Lynette currently serves as Assistant Library Director at Southeastern Louisiana University (SELU). Prior to joining SELU, Lynette served as Associate Director for Public Services at Mercer University, and Associate Director for Access Services at University of Maryland Health Sciences Library. Lynette's areas of interests include Library Administration, emerging technology, and effective and innovative methods of delivering library services.

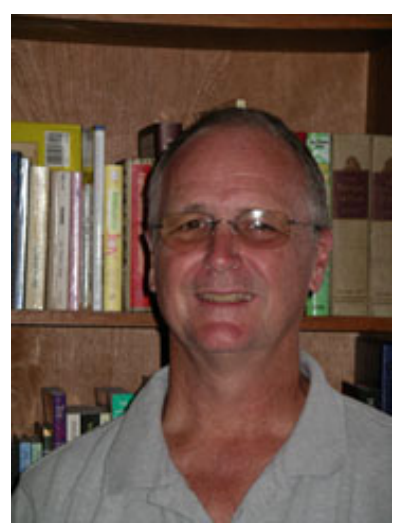

Dr. Timothy Ellis obtained a B.S. degree in History from Bradley University, an M.A. in Rehabilitation Counseling from Southern Illinois University, a C.A.G.S. in Rehabilitation Administration from Northeastern University, and a Ph.D. in Computing Technology in Education from Nova Southeastern University.

He joined NSU as Assistant Professor in 1999 and currently teaches computer technology courses at both the Masters and Ph.D. level in the School of Computer and Information Sciences. Prior to joining NSU, he was on the faculty at Fisher College in the Computer Technology department and, prior to that, was a Systems Engineer for Tandy Business Products. His research interests include: multimedia, distance education, and adult learning.

He has published in several technical and educational journals including Catalyst, Journal of Instructional Delivery Systems, and Journal of Instructional Multimedia and Hypermedia. His email address is ellist@nova.edu. His main website is at http://www.scis.nova.edu/ ellist. 